\title{
Congenital cystic adenomatoid malformation of the lung
}

\author{
M. W. MONCRIEF F, A. H. CAMER ON, R. A S T LEY, \\ K. D. R O BERTS, L. D. A B R A M S, A N D J . M A N N \\ From the Children's Hospital, Birmingham and the Institute of Child Health, Birmingham University
}

Nine cases of congenital cystic adenomatoid malformation of the lung are described. One was stillborn: two presented in the newborn period (one of them surviving after a lobectomy), and the remaining six were older children all of whom survived after lobectomy. There have been only three cases previously reported in children outside the newborn period. The pathological, clinical, and radiological features are discussed and compared with previously reported cases.

Congenital adenomatoid malformation of the lung was a term first used by Ch'in and Tang (1949). They described a stillborn infant who had a large cystic mass involving the lower lobe of the left lung. The distinctive histological features included an epithelial lining which in places was peculiarly similar to the tall mucoid epithelium of the pylorus and colon. They collected 10 cases from the literature and considered that the first description of the pathology of this condition was by Stoerk (1897). Craig, Kirkpatrick, and Neuhauser (1956) reported four more infants, three of whom were successfully treated by lobectomy in the newborn period, and added a further 11 cases from the literature in addition to those collected by $\mathrm{Ch}$ 'in and Tang. They used the word 'cystic' in their description of the condition. Kwittken and Reine $\overrightarrow{0}$ (1962) described in detail the pathological findingso in two cases diagnosed at necropsy. Belanger, La Flèche, and Picard (1964) and Holder and Christ (1964) each reported a case and reviewed the literature. Since then Birdsell, Wentworth, Reilly유 and Donohue (1966) have reported eight cases

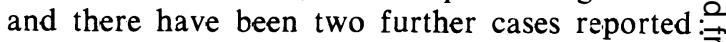
these, together with one case omitted from the previous reviews, are listed in Table I. A total of 47 cases, all but three being infants, have been reported. Twelve have been treated successfully by either lobectomy or pneumonectomy ; the remain $\overline{0}$ der have died or were stillborn.

At the Children's Hospital, Birmingham, there have been nine cases in the last 12 years. Seven

T A B L E I

CASES REPORTED SINCE 1964 AND ONE ADDITIONAL CASE

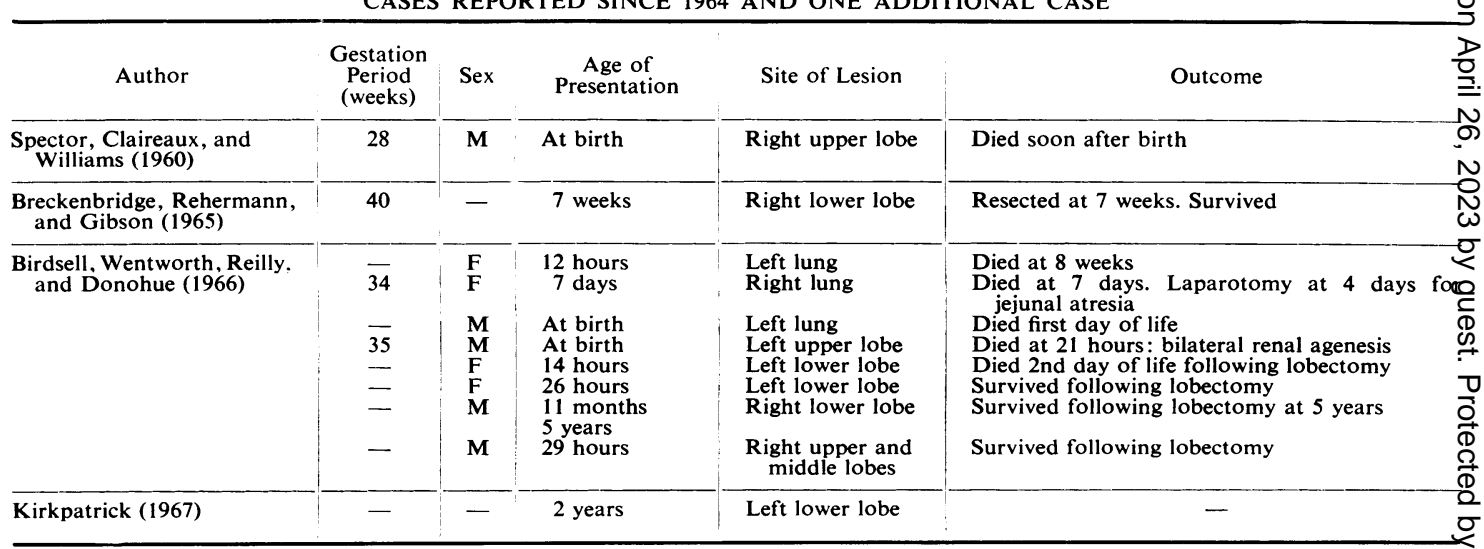


of these have been treated successfully and six of them presented after infancy, the oldest being 12 years of age (Table II).

T A B L E I I

\begin{tabular}{|c|c|c|c|c|}
\hline $\begin{array}{l}\text { Case } \\
\text { No. }\end{array}$ & Sex & $\begin{array}{l}\text { Age of } \\
\text { Presenta- } \\
\text { tion }\end{array}$ & $\begin{array}{l}\text { Site of } \\
\text { Lesion }\end{array}$ & Outcome \\
\hline 1 & $\mathbf{F}$ & Stillborn & Right lower & 一 \\
\hline 2 & $\mathbf{F}$ & At birth & $\begin{array}{l}\text { Left upper } \\
\text { lobe }\end{array}$ & $\begin{array}{l}\text { Survived after lobectomy on } \\
\text { third day of life }\end{array}$ \\
\hline 3 & $\mathbf{F}$ & 3 days & $\begin{array}{l}\text { Left lower } \\
\text { lobe }\end{array}$ & $\begin{array}{l}\text { Left pneumonectomy third } \\
\text { day. Died }\end{array}$ \\
\hline 4 & $\mathbf{F}$ & 22 months & $\begin{array}{l}\text { Right lower } \\
\text { lobe }\end{array}$ & $\begin{array}{l}\text { Survived following } \\
\text { lobectomy }\end{array}$ \\
\hline 5 & $\mathbf{M}$ & 4 years & $\begin{array}{l}\text { Left lower } \\
\text { lobe }\end{array}$ & $\begin{array}{l}\text { Survived following } \\
\text { lobectomy }\end{array}$ \\
\hline 6 & $\mathbf{M}$ & 4 years & $\begin{array}{l}\text { Right upper } \\
\text { lobe }\end{array}$ & $\begin{array}{l}\text { Survived following } \\
\text { lobectomy }\end{array}$ \\
\hline 7 & $\mathbf{M}$ & 5 years & $\begin{array}{l}\text { Left lower } \\
\text { lobe }\end{array}$ & $\begin{array}{l}\text { Survived following } \\
\text { lobectomy }\end{array}$ \\
\hline 8 & $\mathbf{M}$ & 9 years & $\begin{array}{l}\text { Right lower } \\
\text { lobe }\end{array}$ & $\begin{array}{l}\text { Survived following } \\
\text { lobectomy }\end{array}$ \\
\hline 9 & F & 12 years & $\begin{array}{l}\text { Right lower } \\
\text { lobe }\end{array}$ & $\begin{array}{l}\text { Survived following } \\
\text { lobectomy }\end{array}$ \\
\hline
\end{tabular}

\section{CASE REPORTS}

CASE 1 A female infant was stillborn at term. The mother was Rhesus positive and developed toxaemia of pregnancy and hydramnios. Labour was complicated by primary uterine inertia. The head was delivered by forceps, but traumatic decapitation occurred during attempts to deliver the shoulders. Labour was obstructed by the distended foetal abdomen and 1.5 pints $(840 \mathrm{ml}$.) of fluid were withdrawn before delivery could be completed.

Necropsy There was moderate maceration and generalized oedema. The placenta was large, hydropic, and extensively infarcted. The lower lobe of the right lung was entirely replaced by a large, firm tumour mass which filled the right side of the chest. It was grooved laterally by the ribs and medially by the mediastinal structures. The mediastinum was displaced to the left and the left lung and remaining lobes of the right lung were hypoplastic. There was atresia of the terminal ileum, the mesentery was unfixed, and the appendix could not be found. The lungs, including the tumour, were inflated by injection of formalin via the bronchi. Examination after fixation showed that the cut surface of the tumour had many small cystic cavities, the intervening tissue being of firm spongy texture (Fig. 1).

Histology The right lower lobe consisted of large irregular spaces with thin walls. The epithelium had been lost due to maceration, but the walls contained abundant elastic fibres. The spaces communicated with smaller sacs about the size of alveolar ducts but having no related alveoli. Some of these sacs had a recently detached lining of large columnar mucoid cells.

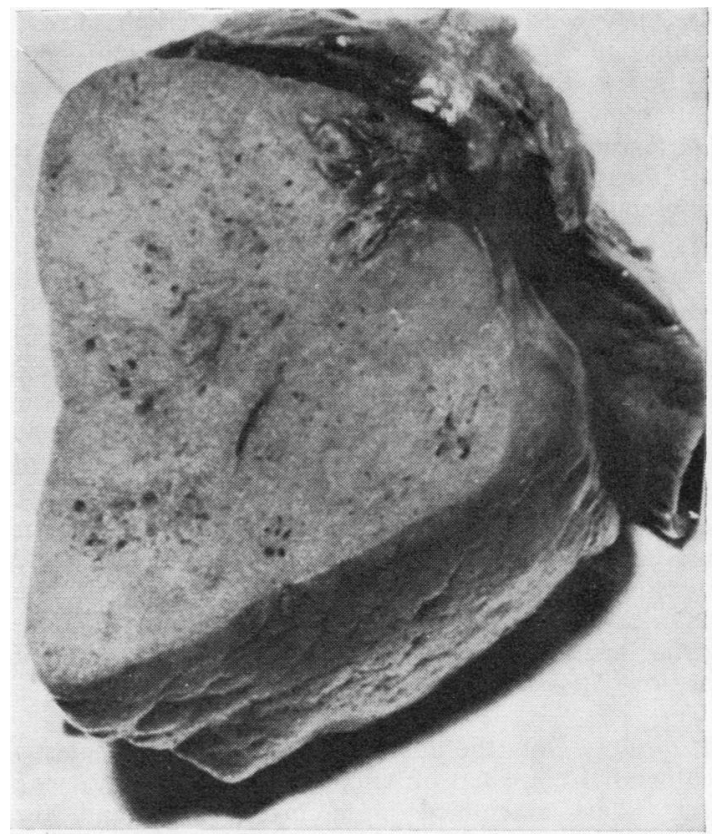

FIG. 1. Case 1. There is massive enlargement of the right lower lobe; the cut surface shows no normal tissue and contains many small cysts. The upper and middle lobes are small.

CASE 2 A female infant was noted to have respiratory distress at birth, becoming progressively more severe and her chest radiograph showed cystic spaces in the left lung. She became cyanosed and dyspnoeic with much lower costal recession: the mediastinum was displaced to the right, and no breath sounds could be heard over the left lung. Thoracotomy was performed on the third day of life and the upper lobe of the left lung was removed. The post-operative period was uneventful and she was well when seen three months later.

The resected lobe contained a large loculated cyst centrally, surrounded by smaller cysts. All the spaces communicated with the bronchi. A narrow crescent of normal lung tissue lay on the medial aspect and extended into the lingula, which was unaffacted.

Histology The cystic and spongy areas contained irregular bronchiolar-like structures with numerous papillary projections. The lining was usually cuboidal or columnar, but in several areas the epithelium consisted of tall mucus-secreting columnar cells (Fig. 2).

CASE 3 This female infant, born by a normal delivery at term, became cyanosed, dyspnoeic, and reluctant to feed on the third day of life. There was intercostal recession, more severe on the right side. The left hemi-thorax was distended and hyper-resonant and the breath sounds were diminished. The mediastinum 
was displaced to the right. A chest radiograph showed a mottled appearance and a number of small cysts in the left lung (Fig. 3). Additional oxygen was given and she improved initially, but later deteriorated. Thoracotomy was performed on the 8th day and the left lung was removed. The infant failed to breath spontaneously after the operation and died one hour later.

Necropsy Examination was performed for H.M. coroner and the thoracic organs were received for examination. The right lung was collapsed and haemorrhagic and the left consisted mainly of the lower lobe which was much enlarged and capped by a small compressed upper lobe. The cut surface of the lower lobe was pale, firm, and cystic (Fig. 4). Most cavities were 2 to $3 \mathrm{~mm}$. in diameter, but larger ones in the periphery measured up to $2 \mathrm{~cm}$., and injection showed that they communicated with the main bronchus. A thin crescent of compressed noncystic lung invested the upper and medial aspects of the lower lobe.

Histology Only the left lower lobe showed dysplastic features. It consisted of thin-walled spaces of varying size. Some resembled wide bronchioles, and the smaller ones resembled alveoli but were as large as normal alveolar ducts. Papillary projections were common and the epithelial lining was mainly ciliated.
Tall mucoid cells were seen in several places and in some of the spaces there were a few polymorphs and aspirated squames.

CASE 4 A little girl was admitted to hospital at the age of 22 months with a one-month history of cough? and dyspnoea. She had a temperature of $100^{\circ} \mathrm{F}$ ) and her respiratory rate was $60 /$ minute. The percussion note was resonant on both sides of the chest but breath sounds were diminished over the righ lung. The mediastinum was displaced to the left. AD chest radiograph showed a large cyst in the right lungt and opacities in the left lung. Thoracotomy was per formed and the cyst, which was in the lower lobe, wast resected as far as possible. The remainder of the lobet looked normal and lobectomy was not performed Post-operatively she developed a tension pneumothorax when the chest drainage tube was removed? and this happened on two subsequent attempts to remove the tube. In view of this and of the pathoऽ logical findings in the resected cyst, lobectomy was performed. Her post-operative recovery was unevent $\vec{\imath}$ ful and she was well when seen three months later. of

Histology (a) The resected portion of the cyst was thin-walled with slight thickening of the overlyins pleura.

The lining consisted of respiratory type epitheliumo partly ciliated, and there were one or two patches of

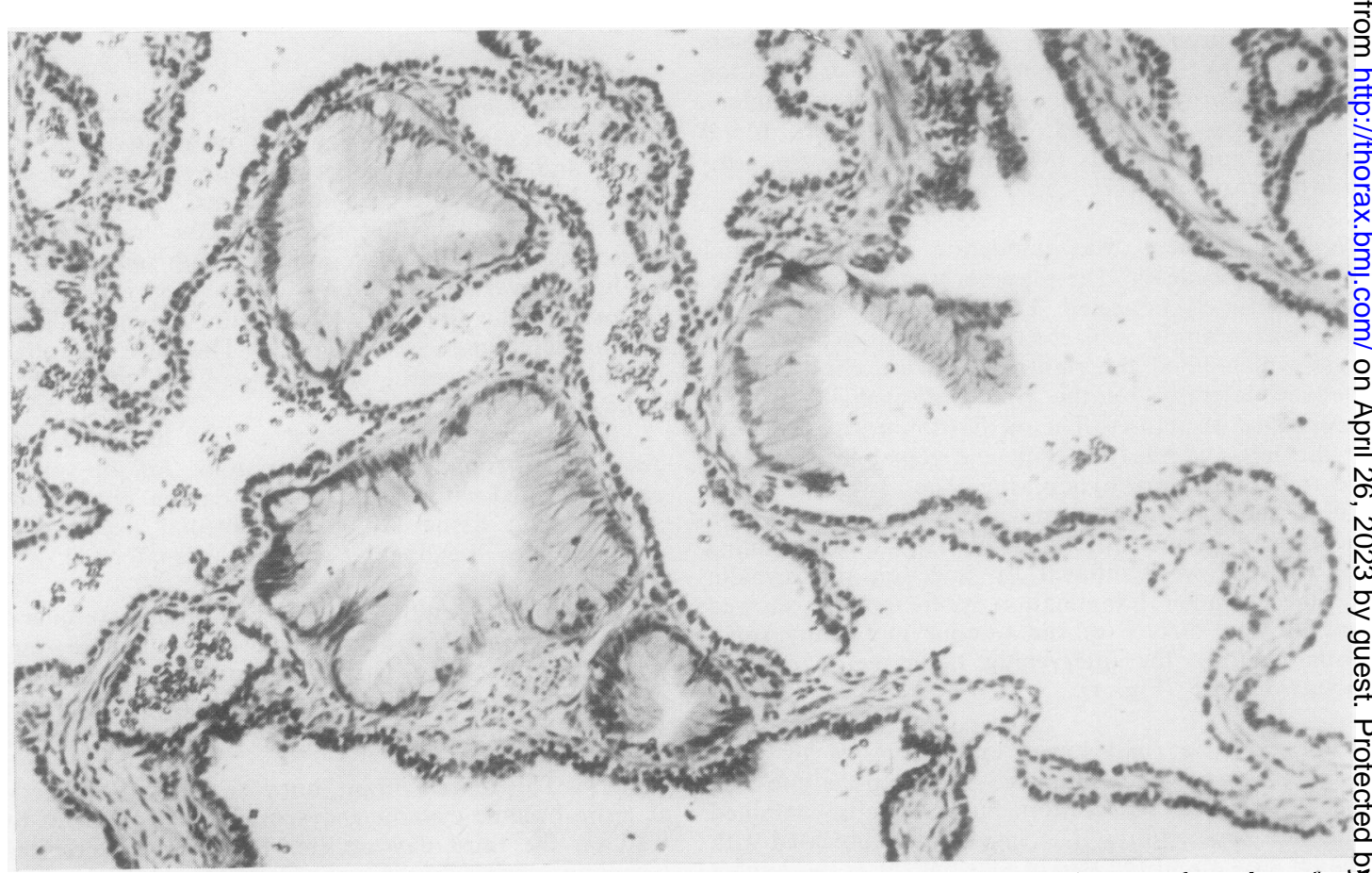

FIG. 2. Case 2. The dysplastic lung consists of irregular thin-walled spaces with a cuboidal lining and patches of tait mucoid epithelium (H. and $E . \times 78)$. 
tall mucoid epithelium. The wall contained muscle and elastic tissue but no cartilage. The cyst communicated with several smaller cavities resembling bronchioles, and many adjacent alveoli contained siderophages.

(b) The lobectomy specimen contained a large cyst in its upper part with disruption of the overlying pleural surface in the two areas. The wall was partly trabeculated, and on the apical side there were smaller cystic cavities which injection showed to be in communication with the main bronchus (Fig. 5).

The histological appearances were similar to those in the resected portion.

CASE 5 A 4-year-old boy had been 'off colour' for a few months with frequent coughs and colds. There was no acute illness or sudden worsening of his symptoms. He was admitted to hospital with a temperature of $100^{\circ} \mathrm{F}$. and a respiratory rate of $58 /$ minute. The left side of the chest moved poorly and was hyper-resonant, and the breath sounds were diminished. A chest radiograph suggested a pneumothorax with collapse of the left lung, except for small areas at the apex and at the base which were adherent to the chest wall. Several unsuccessful attempts were made to aspirate the 'pneumothorax'. The final attempt caused a complete pneumothorax as seen on the radiograph, and it was then thought that the underlying condition was probably a pulmonary cyst. Thoracotomy was perfomed and the lower lobe of the left lung was removed. Recovery was uneventful and at follow-up examination a year later he was quite well.

The resected lobe was largely cystic and distended with air so that much of it was translucent. The apical, hilar, and basal portions were of normal appearance. The remainder consisted of a large cystic cavity bounded laterally by thickened pleura and medially by prominent trabeculae covering the normal lung tissue.

Histology The cavity was lined by a respiratory type of epithelium, mainly ciliated. The wall usually contained thin layers of muscle and elastic tissue and showed a few papillary projections. The cystic cavities appeared to communicate with adjacent alveoli.

CASE 6 A 4-year-old boy had had a persistent cough for a year after measles and was referred to hospital. On examination the percussion note over the right upper lobe was normal, but the breath sounds were diminished and the mediastinum was displaced to the

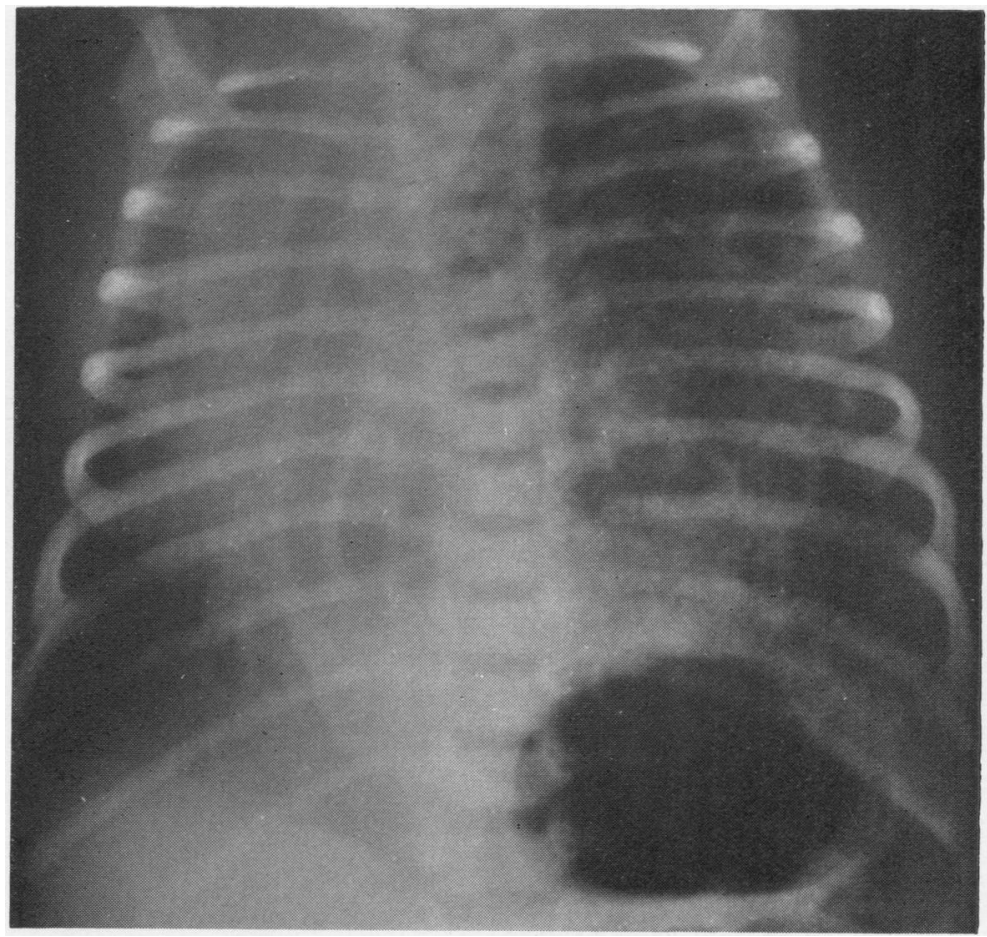

FIG. 3. Case 3. There is a mottled opacity in the left lung, with a number of small incompletely demarcated cysts, especially at the apex. The mediastinum is displaced to the right. 


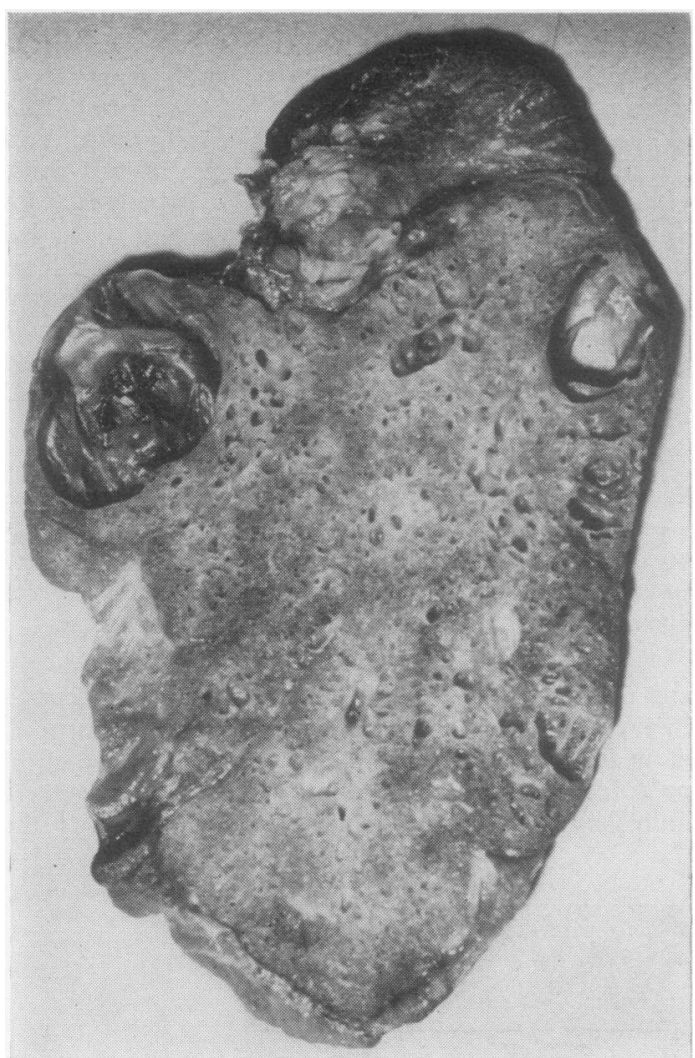

FIG. 4. Case 3. The excised left lung shows massive enlargement of the lower lobe; the cut surface shows many small and two large cysts. There is a small crescent of upper lobe at the top, and below it is a narrow zone of normal lower lobe.

left. A chest radiograph showed a cyst in the right upper lobe and a bronchogram showed that the cyst was in the antero-inferior part of the right upper lobe, which was overdistended. The bronchi of the anterior segment of the upper lobe, and the middle and lower lobes were crowded together at the right base, below and behind the cyst. Only a limited bronchial delineation could be obtained in the posterior and apical segments of the upper lobe. This suggested that the abnormality was not limited to the cyst, and congenital adenomatoid malformation of the lung was considered to be a possibility. A right upper lobectomy was therefore performed. The post-operative period was uneventful and the child was discharged home in good health.

The excised lobe showed adhesions covering a slightly protruding area on the antero-lateral surface, and the surrounding pleura was highly vascular. The protrusion was due to a cyst, $4.5 \mathrm{~cm}$. in diameter, containing slightly mucoid fluid. Much of the remainder of the lobe had a honeycomb appearance with several cysts of up to $1 \mathrm{~cm}$. in diameter, but n⿳亠丷厂犬 evident fibrosis. Injection showed that these areas, but not the large cyst, communicated with the bronchus.

Histology The main cyst had a thin fibrous wall an an epithelial lining, mainly ciliated and pseudo stratified, but partly cuboidal and in places tall and mucoid. The smaller cavities resembled large irregula $\vec{b}$ bronchioles with occasional papillary processes: the lining was mainly of ciliated respiratory type with fairly numerous tall mucoid patches, and these cavities communicated with thin-walled spaces resem bling alveolar ducts, but having no alveolar pouchesin CASE 7 Unfortunately the full case notes of this 5 year-old boy have been lost. The radiological records show that he had suffered from recurrent chest infeco tions since infancy. A chest radiograph indicated $\vec{a}$ cystic condition of the left lung (Fig. 6) and a left lower lobectomy was performed. Post-operative recovery was good and at follow-up examination 10 months later he was well.

The resected lobe was much expanded by a largeo bulging cyst which occupied all but its lateral and medial segments. Injections showed that the cys communicated with the main bronchus, there being many small obliquely placed orifices in the walp Laterally, the cyst wall and pleura formed a thin covering membrane, but medially there was trabecula@ tion and partial loculation.

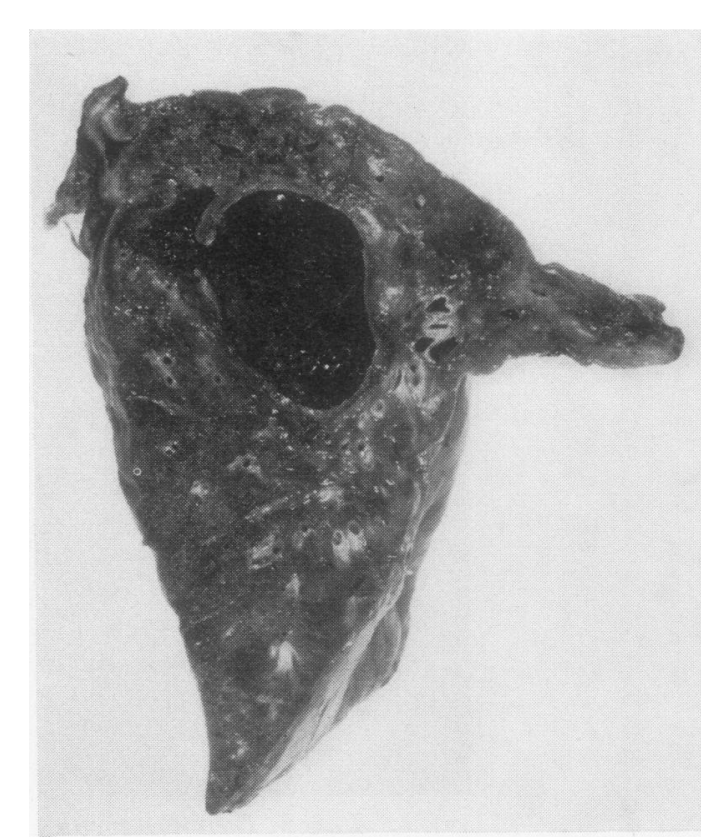

FIG. 5. Case 4. The lobectomy specimen with a large cys in its upper part and a few small adjacent cavities. 
Histology In places the wall was represented by fibrous tissue, but elsewhere there was an epithelium of respiratory, cuboidal or squamous type with thin layers of muscle and elastic tissue. The cyst communicated with wide bronchiolar-like spaces of similar structure, with small papillary projections. The adjacent lung showed moderate inflammatory changes in the bronchi and small foci of pneumonia.

CASE 8 A 9-year-old boy who had previously been in excellent health was seized with sudden pain in the epigastrium while jumping. His temperature was $99^{\circ} \mathrm{F}$. and he was not dyspnoeic. Chest movement was impaired on the right side, which was hyperresonant, and the mediastinum was displaced to the left. An initial diagnosis of a tension pneumothorax was confirmed by a chest radiograph and an intercostal tube was inserted and connected to an underwater-seal drain with escape of a considerable amount of air (Fig. 7a, b). A second chest radiograph showed expansion of the right upper lobe with some air in the lower half of the chest. However, when the tube was removed two days later the lung again collapsed and a further chest radiograph suggested an abnormal cyst-containing lung. Thoracotomy was performed and the right lower lobe was removed. Following this, progress was uneventful and 14 months later he was in good health.

The resected lobe showed a large cyst with a thin bulging lateral wall with two small perforations. The

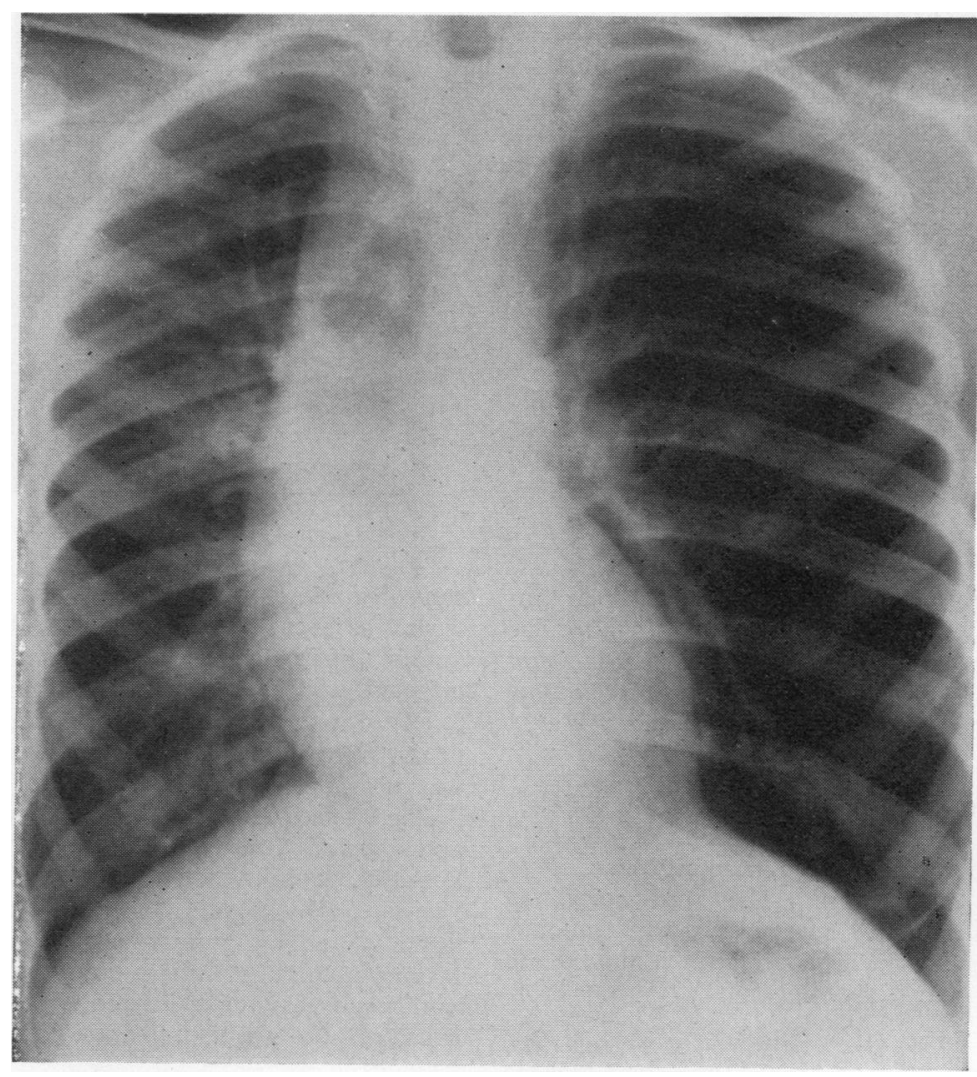

(a)

FIG. 6. Case 7. Overdistension of part of the left lung displacing the mediastinum to the right and depressing the left dome of the diaphragm. Compressed vascular markings of the uninvolved part of the left lung can be seen medially. In the frontal projection (a), there is very little indication of the boundary of the cystic area but a thin curved line in the left costophrenic sulcus is a clue. The left anterior oblique view (b, overleaf) is more successful in showing the thin, curving white line around the cystic area (seen behind the heart shadow). 


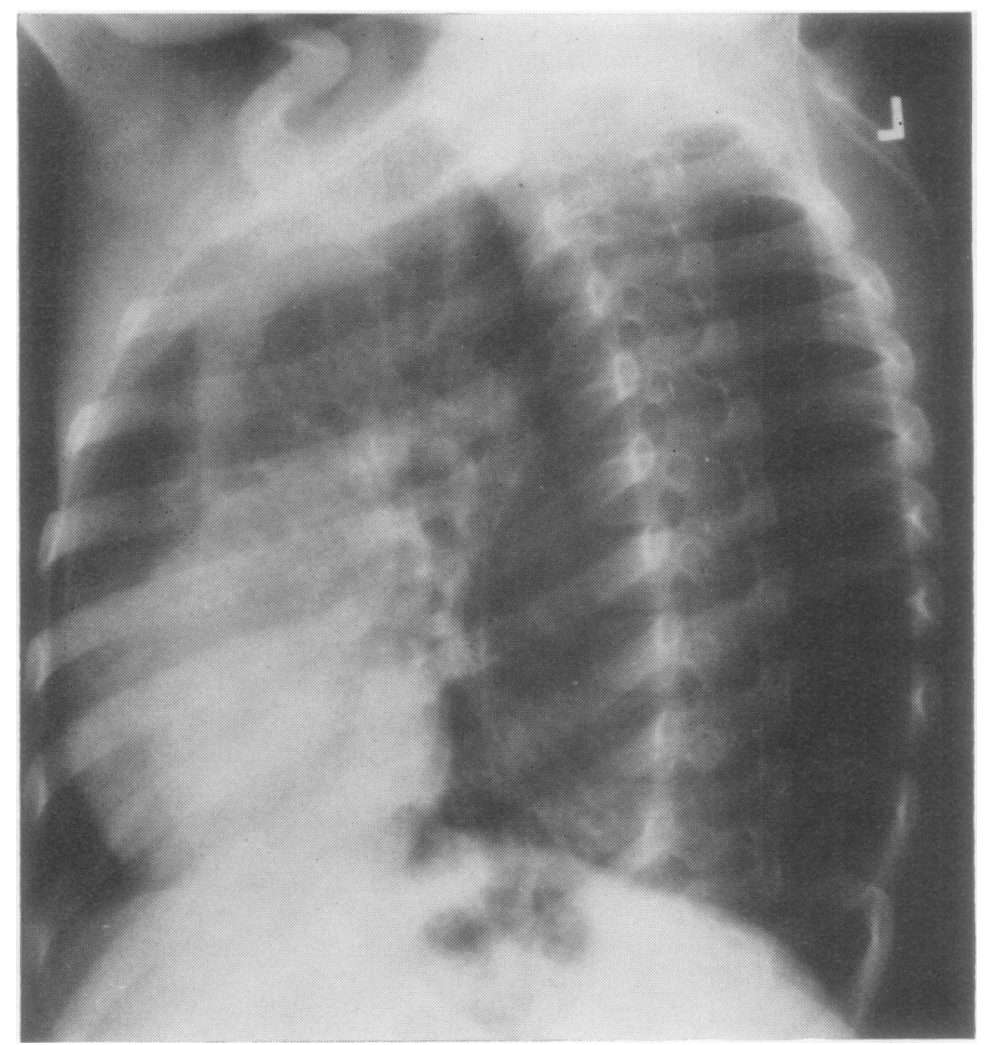

FIG. 6 (b)

cyst replaced all but the dorsal segment and a thin basal segment of the lobe. There was much trabeculation where it bordered the unaffected areas, and towards the hilar aspect there were several similar, smaller cysts.

Histology The large and small cysts had an epithelial lining, sometimes cuboidal and sometimes ciliated; patches of tall mucoid cells were commonly seen, some showing papillary hyperplasia. The wall contained muscle and elastic tissue and occasional mucous glands. The cystic cavities appeared to communicate with adjacent ducts and alveoli.

CASE 9 A 12-year-old girl first developed chest trouble three weeks before admission when she fell over a chair and later complained of pain in the lower part of the right side of her chest, which persisted for six days. She felt unwell and breathless and later developed a cough and fever. Her temperature was $103^{\circ} \mathrm{F}$. and her respiratory rate $52 /$ minute. The right side of the chest moved poorly, the percussion note was impaired, and breath sounds were diminished. The mediastinum was not displaced. An empyema was suspected and $50 \mathrm{ml}$. of pus were aspirated. A chest radiograph later showed a multio cystic cavity on the right side containing a large amount of fluid, and it was then clear that she had as infected pulmonary cyst rather than an empyema (Fig. 8). Thoracotomy was performed and the lower lobs of the right lung was removed. Post-operative progres was satisfactory and she was well one year later.

The excised lobe was covered with fibrous exudate and showed fibrous thickening of the pleura anteres laterally. It contained a large cyst, about $160 \mathrm{ml}$. in volume, which was covered by thickened pleurf laterally and by compressed lung on its other aspects. It had a thick yellowish lining showing many sma nodules on its inner aspect and minor trabeculation Injections did not demonstrate communication with the bronchi.

Histology The lining consisted of granulation tissue and acute inflammatory exudate, except for a few areas where there was an epithelium of cuboidat squamous or ciliated respiratory type. One small patc of tall mucoid epithelium was seen. The cyst appearea to communicate with adjacent bronchi and with wid\& bronchiolar-like structures of irregular contoug Adjacent lung tissue showed compression-collapse ang areas of organizing pneumonia. 


\section{DISCUSSION}

Congenital cystic adenomatoid malformation of the lung has several distinctive pathological features. It shows no preference for either side or for the upper or lower lobes; our nine cases are unusual in that the lesion involved the lower lobe in seven. With few exceptions (Goodyear and Shillitoe, 1959) only one lobe is affected. The proportion of the lobe involved varies considerably and our cases show much more extensive involvement in younger children. It is understandable that the smaller lesions may not cause complications until many years have passed. For example, the whole lobe was involved in our stillborn case whereas the eldest child (aged 12 years), showed a large amount of compressed but other- wise normal lung tissue in the affected lobe (compare also Figs 1, 4, and 5).

The age of the child also has a bearing on the size of the cysts within the lesion. The abnormal lung tissue consists of potential spaces which are in communication with the bronchi and tend to open up with the onset of respiration. As Craig et al. (1956) have pointed out, the malformed air passages have soft non-cartilaginous walls which tend to collapse during expiration and lead to airtrapping with further distension of the cystic spaces. In the older child, therefore, the lesion consists largely of trapped air, but in the newborn it forms a more solid tumour mass. The demonstration, by injection, of communication with the main bronchi is of great diagnostic importance and should be attempted early in the laboratory

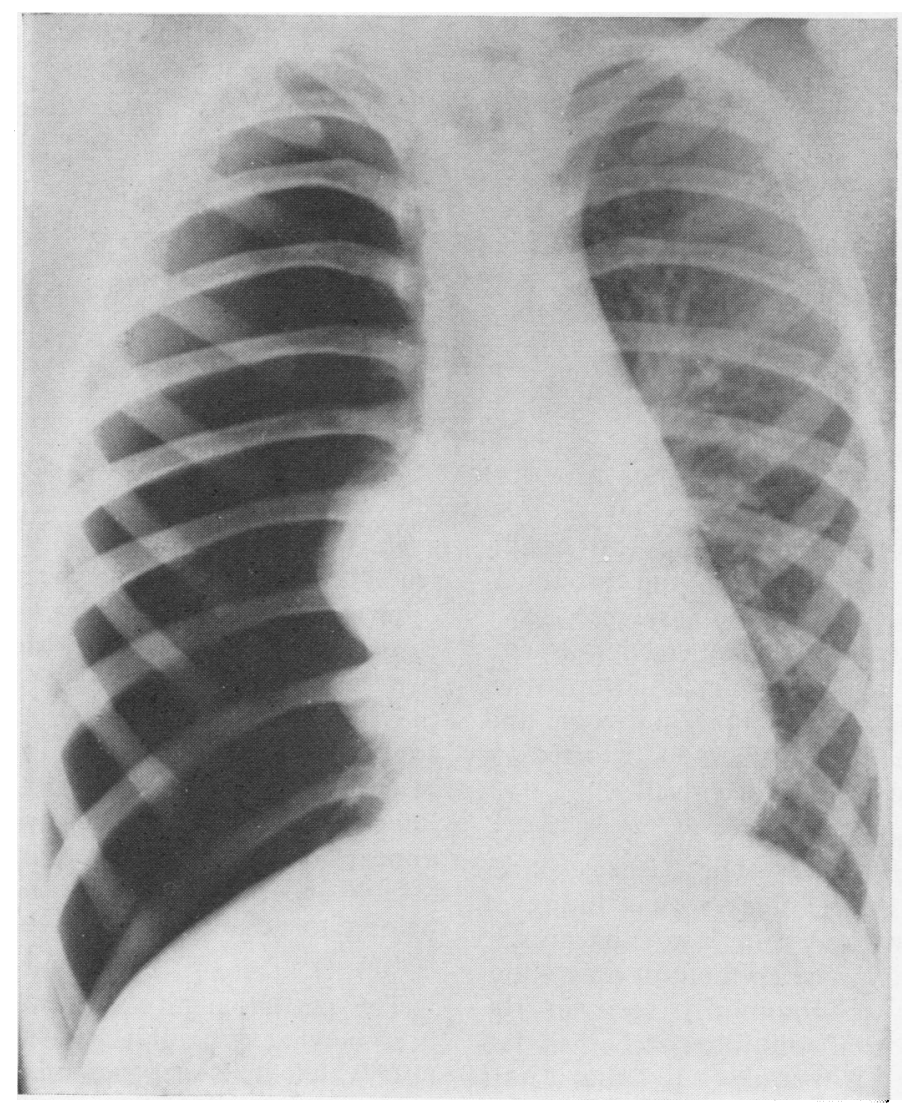

(a)

FIG. 7. Case 8. (a) Right-sided tension pneumothorax with collapse of the right lung. The cystic nature of the collapsed lower lobe can be suspected. ( $b$, overleaf). After removal of pleural air, the right lower lobe is seen to be overdistended and partly surrounded by a curving white line, while thin lines incompletely transverse its interior. The mediastinum is displaced to the left. 


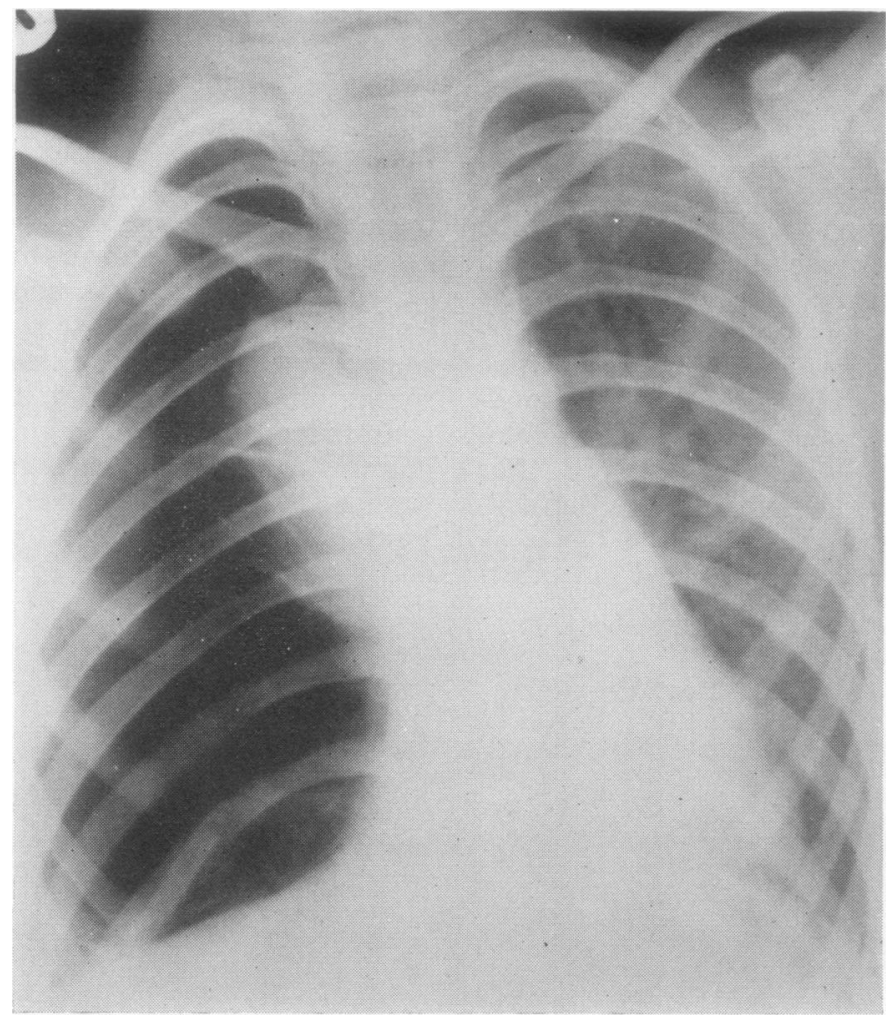

FIG. 7 (b)

examination; it serves to distinguish this condition from those of sequestration and bronchial atresia. The margin of the lesion characteristically has no capsule and may be difficult to define with precision. The larger cysts in older children often have small cystic spaces in the marginal zone, and when these become flattened and distorted, a typically trabeculated appearance results.

Histological examination shows the basic structure of a respiratory unit. The larger spaces resemble overgrown bronchioles with a lining of respiratory epithelium and thin layers of muscle and elastica in the wall. The epithelium may show metaplasia, such as is commonly seen in the respiratory tract, and in addition patches of tall mucoid cells. This is similar to that normally seen in the colon and to that in so-called 'alveolar' or 'bronchiolar' carcinoma of lung, and is a pathognomonic feature which should be searched for in sections taken from different areas; it was found in seven of our nine cases. Another characteristic feature is that there are commonly papillary projections from the wall, even when the cystic cavity appears to be distended, and one might expect to find atrophic aso opposed to proliferative changes. The papillae may consist of epithelium only or include the under-o lying muscle and elastica. This shows that even₹ the lesions from the older children retain theiro capacity for growth. Most of the smaller spaces resemble alveolar ducts but show no alveolaro pouches. Often the cystic spaces in the margins appear to communicate with relatively normalo alveoli and it is difficult to be sure whether these $N$ belong to adjacent lung tissue or are part of the $\mathrm{W}^{\mathrm{N}}$ lesion.

The pathological classification of the conditione is somewhat debatable but we agree with Thomas (1949) that it is a proper member of that peculiar? group of so-called 'hamartomata' which falls between the true neoplasm and the malformation. The lesion must not be confused with the pre-@ dominantly cartilaginous hamartoma of adults. It $\stackrel{\mathbb{Q}}{\varrho}$ is important to realize that these children areo usually free from such lesions elsewhere, and the associated malformations in our first case appearo 


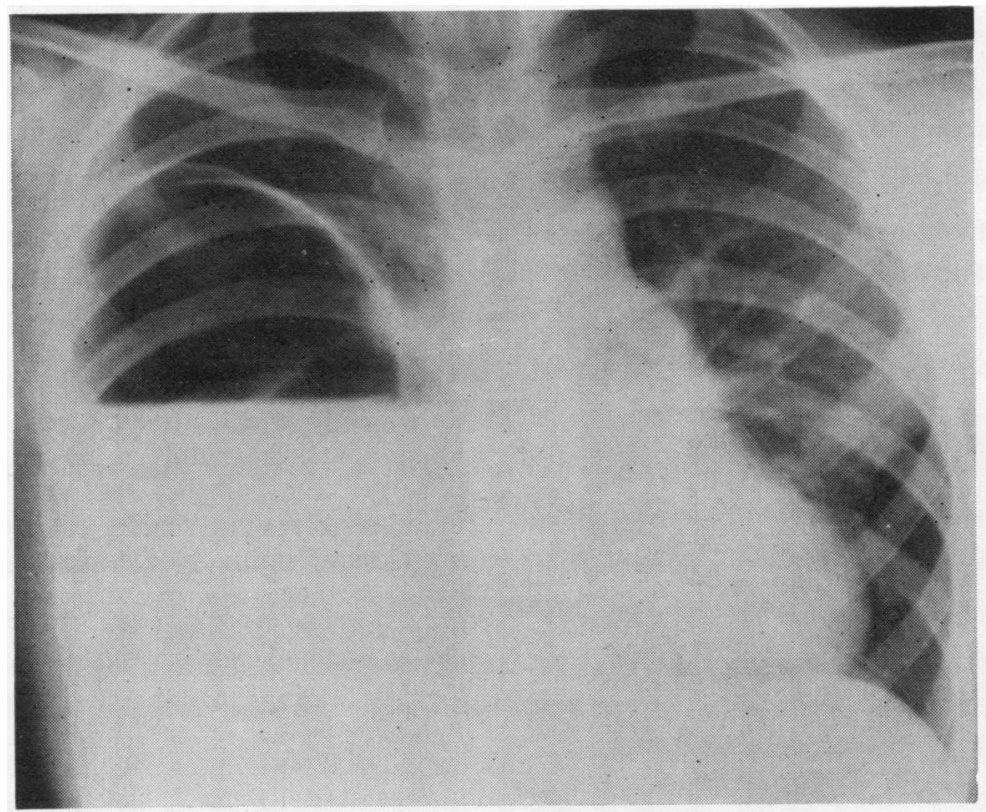

(a)

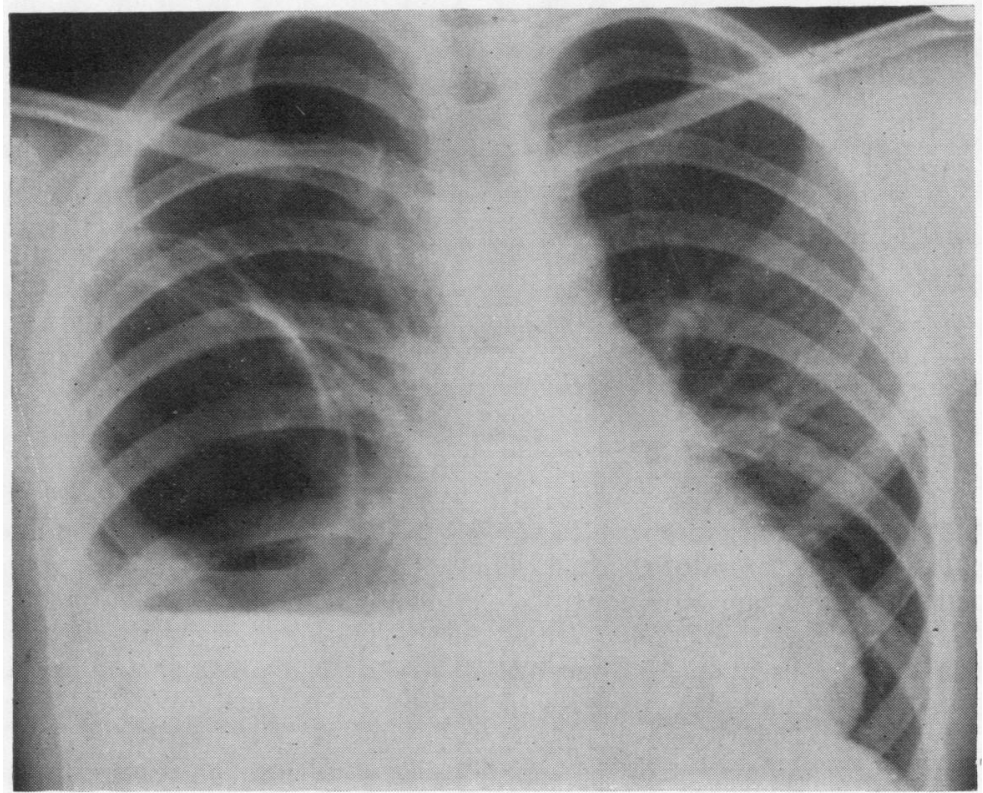

(b)

FIG. 8. Case 9. (a) The initial radiograph shows an air-fluid level with a welldefined, curved white boundary line between the air and the compressed lung in the apex. The mediastinum is displaced to the left. (b) After aspiration of pus, the multi-cystic nature of the right lower lobe is more apparent. 
to be purely coincidental. In our experience this is the commonest type of cystic malformation of the lung, and it appears to be much more frequent than the published reports suggest. The cases fall into three groups-stillbirths, neonates, and those who present in later childhood. The last group form the bulk of our patients but a small minority of the reported cases. This discrepancy cannot be accounted for by selection of the children who attend our hospital as this caters for all ages and the newborn in particular.

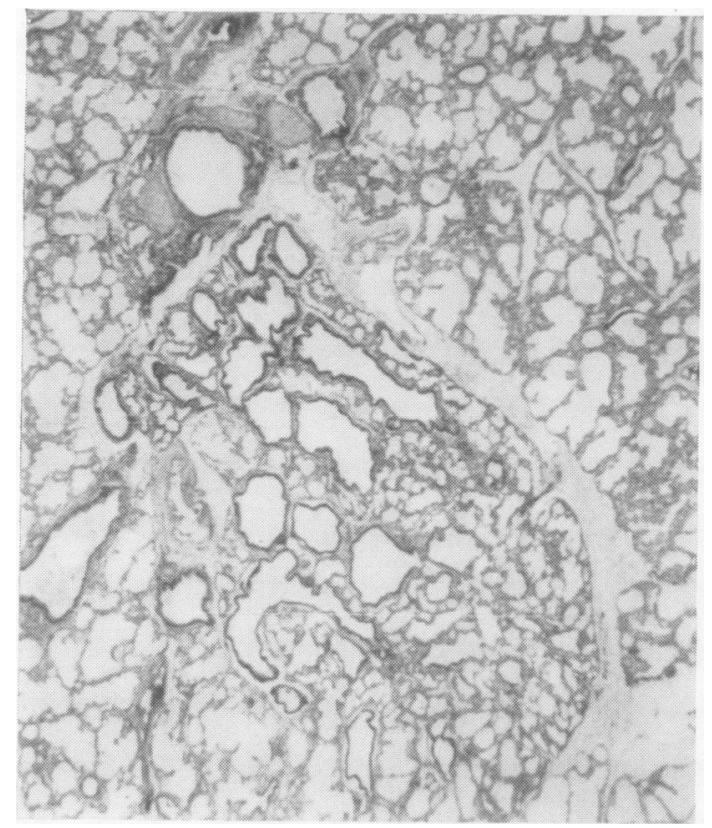

FIG. 9. An incidental necropsy finding. There is a small segment of dysplastic lung below and to the right of the normal bronchus in the upper part of the picture $(H$. and $E$. 16).

Eleven of the published case reports were of stillborn babies. Labour was premature in all and there was hydramnios in three. Eight of the babies had generalized oedema which could be confused with hydrops foetalis due to severe Rhesus haemolytic disease. Our first case falls in this group and showed a large, firm tumour mass. We agree with Gottschalk and Abramson (1957), who consider that the oedema is due to the mass causing obstruction to the venous return to the heart.

Our second and third cases developed severe respiratory distress in the newborn period. Thirtythree of the 47 reported cases belong in this group. Many were born prematurely and some died soon after birth. Clinical examination suggests either a pneumothorax or a solid lung and the mediastinum is widely displaced. The clinical diagnosis is from other conditions causing a large shift of the mediastinum associated with severe respiratory distress, especially lobar emphy sema, pneumothorax, and diaphragmatic hernia.心

A chest radiograph is essential for making the diagnosis and should distinguish these conditions;

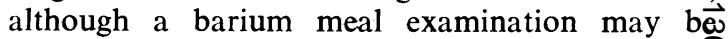
needed to exclude a diaphragmatic hernia. How ever, our two neonatal cases did not show prex dominantly cystic appearances; the affected lobe had a rather 'solid' appearance with mottlea opacity containing a number of fairly smali incompletely demarcated cavities (Fig. 3). Com pression of uninvolved lobes could not be identio fied but there was overdistension of the affected lung with mediastinal displacement to the oppos site side. The differential diagnosis of the radios logical findings has been discussed in detail bof Belanger et al. (1964), but it is not essential to make a preoperative diagnosis of the nature of the cystic condition as urgent thoracotomy is needed. Successful treatment, as in our case 2 , wa first reported by Fischer, Tropea, and Baile ${ }^{\circ}$ (1943), and since then a total of 10 cases arE known to have recovered following surgery in the newborn period.

Our remaining six cases were in older children? whereas only three previous cases have been. reported in children outside the newborn period (Birdsell et al., 1966 (see Table I) ; Caffey, 1961 유 and Kirkpatrick, 1967 ; clinical details of thes\& last two patients are not given). It is remarkable that these children appear to have been com pletely symptomless in early life, as in our case 9 o even for as long as 12 years. Perhaps a recen incidental necropsy finding is of relevance to this A premature male baby died at 11 days with th megacystis syndrome. There had been no respira을 tory symptoms, and the lungs were unremarkablä at necropsy. Histological examination showed tha? part of one segment of one lobe had a dysplastif appearance similar to that in the cases presented above (Fig. 9). The whole area measured less that $0.5 \mathrm{~cm}$. in diameter, and respiratory symptom would have been unlikely to develop for a con siderable time if the infant had lived. As already? noted, the histological appearance of these lesionso suggests that a capacity for continued growth is? maintained, and it is quite possible that the largen cysts in the older children were as inconspicuous as this at birth.

Diagnosis in the older children may be particus larly difficult. The main radiological features iro 
five were overdistension of a major part of one lung and mediastinal shift to the opposite side. Associated features of the over-distension were widening of intercostal spaces and depression of the diaphragm. It was apparent that the whole lung was not involved, as compressed lung could be identified in one or more areas. The distended portion was variable in the definition of its boundary and it was usually incompletely demarcated. However, a curved white boundary line suggesting a cyst was seen in at least some places, especially in oblique or lateral radiographs (Fig. 6). The area of increased translucency might appear to contain somewhat widely spaced vascular markings, really situated in an over- or under-lying region of normal, compressed lung. In addition, there was always a number of thin, incomplete linear opacities within the hypertranslucent area, giving an impression of slight septation.

A frankly multicystic appearance was seen in only two or three. In one child (case 9), where there was a large fluid-level in the main cyst, the radiographs were thought initially to indicate a loculated empyema ; indeed, the fluid removed was pus but post-aspiration radiographs revealed the underlying lung to be multicystic (Fig. 8). Similarly, case 7 of Birdsell et al. (1966) had a pulmonary abscess and the underlying cystic condition of the lung was not suspected initially. Our case 5 had an insidious onset of respiratory symptoms and the cystic area of the lung was so distended with air as to mimic the clinical and radiological features of a pneumothorax. In case 8 the presenting feature was a tension pneumothorax with complete collapse of the lung. In retrospect, the lower lobe of the collapsed lung could have been suspected to be cystic from the initial radio- graph but this did not become obvious until after re-expansion, when pleural air had been released (Fig. 7).

The prognosis in older children is even better than in newborn infants, as all our six children have survived and are well.

Our thanks are due to Professor d'Abreu, Professor Wolff, Dr. B. S. B. Wood, and Dr. G. W. Chance for permission to publish details of their patients.

\section{REFERENCES}

Belanger, R., La Flèche, L. R., and Picard, J-L. (1964). Congenital cystic adnomatoid malformation of the lung. Thorax, 19, 1 .

Birdsell, D. C., Wentworth, P., Reilly, B. J., and Donohue, W. L. (1966). Congenital cystic adenomatoid malformation of the lung: a report of eight cases. Canad. J. Surg., 9, 350.

Breckenbridge, R. L., Rehermann, R. L., and Gibson, E. T. (1965). Congenital cystic adenomatoid malformation of the lung. J. Pediat., 67, 863.

Caffey, J. (1961). Pediatric $X$-ray Diagnosis, 4th ed., p. 282. Year Book Medical Publishers, Chicago.

Ch'in, K. Y., and Tang, M. Y. (1949). Congenital adenomatoid malformation of one lobe of a lung with general anasarca. Arch. Path., 48, 221.

Craig, J. M., Kirkpatrick, J., and Neuhauser, E. B. D. (1956). Congenital cystic adenomatoid malformation of the lung in infants. Amer. J. Roentgenol., 76, 516.

Fischer, C. C., Tropea, F., Jr., and Bailey, C. P. (1943). Congenital pulmonary cysts; report of an infant treated by lobectomy with recovery. J. Pediat., 23, 219.

Goodyear, J. E., and Shillitoe, A. J. (1959). Adenomatoid hamartoma of the lung in a newborn infant. J. clin. Path., 12, 172.

Gottschalk, W., and Abramson, D. (1957). Placental edema and fetal hydrops: a case of congenital cystic and adenomatoid malformation of the lung. Obstet. and Gynec., 10, 626.

Holder, T. M., and Christy, M. G. (1964). Cystic adenomatoid malformation of the lung. J. thorac., cardiovasc. Surg., 47, 590.

Kirkpatrick, J. (1967). Progress in Pediatric Radiology, Vol. 1, p. 309. Ed. Kaufmann, H. J., Karger, Basel and New York.

Kwittken, J., and Reiner, L. (1962). Congenital cystic adenomatoid malformation of the lung. Pediatrics, 30, 759.

Spector, R. G., Claireaux, A. E., and Williams, E. R. (1960). Congenital adenomatoid malformation of lung with pneumothorax. Arch. Dis. Childh., 35, 475.

Stoerk, O. (1897). Ueber angeborene blasige Missbildung der Lunge. Wien. klin. Wschr., 10, 25.

Thomas, M. R. (1949). A cystic hamartoma of the lung in a new-born infant. J. Path. Bact., 61, 599. 